\title{
Teacher Role and Involvement in Curriculum Development and Mapping
}

\author{
Amir Toghyani Khorasgani \\ Ph.D. Student in the field of Curriculum Planning, Isfahan (Khorasgan) Branch, \\ Islamic Azad University, Isfahan, Iran
}

\begin{abstract}
In order for curriculum development to be effective and schools to be successful, teachers must be involved in the development process. An effective curriculum should reflect the philosophy, goals, objectives, learning experiences, instructional resources, and assessments that comprise a specific educational program ("Guide to curriculum development," 2006). It can be subject specific or a generalized overview of expectation. It must be a usable tool to assists teachers in the development of individualized strategies and the methods and materials necessary for them to be successful.
\end{abstract}

Keywords: curriculum development, teacher involvement, challenge in curriculum development

DOI: $10.7176 / \mathrm{JEP} / 12-28-01$

Publication date:October $31^{\text {st }} 2021$

\section{Introduction}

The goal of a successful educational program and thus effective curriculum development should be to meet the needs and current demands of the culture, the society, and the expectations of the population being served. Therefore, curriculum development and the educational reform process continually under goes review, revision, and constant change (Johnson, 2001). Curriculum development can be challenging, therefore the involvement of all stakeholders, especially individuals who are directly involved in student instruction, are a vital piece in successful curriculum development and revision (Johnson, 2001). The role of teachers highlighted when we defined the as the complex network of what to teach and how to teach it (Toghyani Khorasgani \& Rahmani, 2019). In practice, Curriculum is a vehicle by which subject matter gets into the classroom and is taught to students and can be said that curriculum usually takes place when the teacher closes the classroom door (Toghyani Khorasgani and Rahmani, 2021). So, this paper will discuss the importance of teachers' involvement in curriculum development, the challenges that teachers face in curriculum development, preparation for teachers' involvement in curriculum development, the teachers' role in curriculum development, and then conclusion.

\section{The Importance of Teachers Involvement in Curriculum Development}

Without doubt, the most important person in the curriculum implementation process is the teacher. With their knowledge, experiences and competencies, teachers are central to any curriculum development effort. Better teachers support better learning because they are most knowledgeable about the practice of teaching and are responsible for introducing the curriculum in the classroom. If another party has already developed the curriculum, the teachers have to make an effort to know and understand it. So, teachers should be involved in curriculum development. For example, teacher's opinions and ideas should be incorporated into the curriculum for development. On the other hand, the curriculum development team has to consider the teacher as part of the environment that affects curriculum (Carl, 2009). Hence, teacher involvement is important for successful and meaningful curriculum development. Teachers being the implementers are part of the last stage of the curriculum development process.

\section{The Challenges Teachers Face in Curriculum Development}

The teachers' involvement in the curriculum development process is essential in meeting the needs of society. The process of curriculum development requires teachers to act and reflect on society's needs in each stage of the development process. Nevertheless, sometimes this process which teachers are requested to follow is unclear. For example, in South Africa most teachers are not qualified and lack the necessary skills to participate in curriculum development. Their approach of participation in the process is not well defined and very difficult on teachers, so they face many challenges regarding their involvement in curriculum development (Ramparsad, 2000). As a result, I think that there should be major advances in teacher development in order for teachers to actively reflect on society's needs in each stage of the curriculum development process. On the other hand, in any curriculum implementation process not all teachers will have the chance to be involved in these processes. Professional development of teachers is as an important factor contributing to the success of curriculum development and implementation (Handler, 2010). So, we should think about what extent teacher education programs are needed for prospective teachers to study curriculum development.

4. Preparation for Teacher Involvement in Curriculum Development 
Because teachers have to be involved in curriculum development, the teacher should be provided with appropriate knowledge and skills that help them to effectively contribute in curriculum development operation.

As a result, teachers need training and workshops, which are geared toward professional development to be able to contribute to curriculum development. On the other hand, there is an important point to make efficient in involvement teacher in curriculum development that is teachers have to be empowered in the process of curriculum development (Carl, 2009). This means teachers should have improvement and increasing in many points of them, such as experience and autonomy. Thus, teachers play an integral part in the process of developing the curriculum; then students' outcomes.

\section{The Teachers Role in Curriculum Development}

The teacher involved in curriculum organization has many roles and responsibilities. Teachers want to enjoy teaching and watching their students develop interests and skills in their interest area. The teacher may need to create lesson plans and syllabi within the framework of the given curriculum since the teacher's responsibilities are to implement the curriculum to meet student needs (Carl, 2009). Many studies support empowerment of teachers through participation of curriculum development. For example, Fullan (1991) found that the level of teacher involvement as a center of curriculum development leads to effective achievement of educational reform. Therefore, the teacher is an important factor in the success of curriculum development including the steps of implication and evaluation. Handler (2010) also found that there is a need for teacher involvement in the development of curriculum. Teachers can contribute by collaboratively and effectively working with curriculum development teams and specialists to arrange and compose martial, textbooks, and content. Teacher involvement in the process of curriculum development is important to align content of curriculum with students needs in the classroom.

\section{Conclusion}

In short, No curriculum will be perfect, a finished product cast in stone, or free from criticism, but to be effective it must be accepted by teachers and must be deemed educationally valid by parents and the community at large ("Guide to curriculum development," 2006). Curriculum development should be viewed as a process by which meeting student needs leads to improvement of student learning. In addition, it cannot be stagnant. Curriculum must be a living document that is in constant flux. It must be adaptable to changes in the educational community and in society in general. Only then will it be able to be an effective change agent in the educational process. The change journey comes in many phases, where collaboration and feedback are important (Glickman, Gordon \& Ross-Gordon, 2013, p. 293). Teachers and supervisors gather and collect data, reflect with dialogue, and make informed decisions together. Instructional leadership is shared with teachers, in its most progressive forms it is being cast as collegial investigation, reflection, and coaching (Blasé, 1999, p. 350). Problems and conflict do happen, but "problems are our friends" (Glickman, Gordon \& Ross-Gordon, 2013, p. 293). Problems need to be embraced so that the organization can come up with a reasonable solution or solutions. Finally, for schools to be successful with change and development, they must believe that creating a culture of continuous improvement is the way to adapt to changing needs and conditions. Schools need to continuously assess themselves and have the goal toward self-actualizing (Glickman, Gordon \& Ross-Gordon, 2013, p. 293). Thus, schools are never perfect or self-actualized.

\section{References}

Blasé, Joseph (August, 1999) Principals' Instructional Leadership and Teacher Development: Teachers' Perspectives. Educational Administration Quarterly, Vol. 35, p. 349-378.

Carl, A. (2009). Teacher empowerment through curriculum development theory into practice. Juta\&Company Ltd. Education, Inc.Bureau of Curriculum and Instruction Connecticut State Department of Education. (2006, November 3). Guide to Curriculum Development: Purposes, practices, Procedures. In Connecticut State Department of Education.

Fullan, M. (1991). The meaning of educational change. New York: Teacher College Press.

Glickman, C. D., Gordon Glickman, C. D., Gordon, S. P., \& Ross-Gordon, J. M. (2013). The basic guide to supervision and instructional leadership (3rd ed., pp. 250-262). Boston: Pearson.

Handler, B. (2010). Teacher as curriculum leader: A consideration of the appropriateness of that role assignment to classroom-based practitioners. International Journal of Teacher Leadership. Volume 3. ISSN: 1934-9726.

Johnson, J. A. (2001, August 28). Curriculum revision that works. In principles of effective change. Retrieved March 10, 2014

Ramparsed, R .(2000). A strategy for teacher involvement in curriculum development. South African Journal of Education.

Toghyani Khorasgani A., Rahmani J. (2019). Curriculum Planning based on Economic Knowledge in Some Developed Countries. IJRDO - Journal of Educational Research (ISSN: 2456-2947), 4 (5), 13-27. 
Retrieved from https://www.ijrdo.org/index.php/er/article/view/2836

Toghyani Khorasgani A., Rahmani J. (2021). Economics Across the School Curriculum-Benefits and Drawbacks of Some Related Approaches. International Journal of Education, Culture and Society; Feb 2021; 6(1): 9-14; ISSN: 2575-3363 (Online); Doi: 10.11648/j.ijecs.20210601.12 